\title{
Introduction to Re@ct: Social Change Art Technology
}

\author{
JOSEPH DELAPPE \\ Professor of Games and Tactical Media, Abertay University, Dundee
}

\author{
LAURA LEUZZI \\ Researcher, SARAS Department at Sapienza University of Rome
}

It was just under two years ago, in November 2019, that we, together with Sarah Cook, served as co-chairs and organizers for Re@ct: Social Change Art Technology, an expanded three-day symposium held in Dundee, Scotland, in partnership with NEoN Digital Arts Festival. In the interim, the world has changed, dramatically so. We have all experienced the ongoing global pandemic that is COVID-19. The killing by police of Breonna Taylor in Louisville and George Floyd in Minneapolis have called into question issues of racial justice and the legacy of slavery in the United States and beyond. We witnessed one of the most consequential presidential elections in the history of the United States, followed by an attempted coup and ongoing efforts to take the USA towards totalitarianism. The attacks on Roe v. Wade put basic civil rights at risk. In the UK everything is backgrounded by the ongoing consequences of Brexit, including growing calls for Scottish independence. Waiting in the wings, of course, is the continuing climate crisis, which has contributed to wildfires raging across southern Europe, California, and Australia, as well as massive hurricanes hitting the Gulf of Mexico - the most recent, Ida, caused deadly flooding in New York City - and the breaking of temperature records all across the planet. To say we are living through interesting times would be an understatement.

From our current context, the Re@ct symposium seems like some distant, yet vital memory of a time and place where we were able to physically engage with a diverse group of thirty international digital artists, scholars, activists, and attendees over three days in Dundee in order to share and discuss a variety of issues and practices being engaged through creative digital arts activism and scholarship.

Our goal was to bring together artists involved in media art and the digital scene who have been prompted to react and respond to local, national, and global social and political crises. Today we see a continuation and intensification of such efforts by media-based, creative practitioners. Through Re@ct we created a platform to critically examine the relevance and impact of past and present practices and, importantly, to develop strategies to engage an uncertain future; to explore the consideration and creation of digitally based artwork that functions to critique, question, and ultimately work towards defining future best practices. What are the current trends and forms of protest, resistance, and reactions by artists working today? How are digital artists providing 
critical approaches to environmentalism, sustainability, LGBTQ rights, equality, economics, pacifism, and politics in their local and in our shared global context?

Re@ct considered the practices of artists, activists, curators, and scholars who engage contemporary media technologies to critically speculate and strategize about how best to use emerging technologies to address our complex social, political, and cultural futures. A primary goal for this symposium was to enable and promote a better understanding of the strategic importance of how media and digital artists are reacting to the current political and social situation and to reassess the importance of activism in the history of the practice, but also to identify, encourage, and foster new practices and future ideas, approaches, and outcomes.

Re@ct was an entirely free symposium. One of the goals of Re@ct: Social Change Art Technology was to disrupt, question and rethink how to present such a symposium. We created a uniquely open and accessible event that, by design, moved between four venues across Dundee over the three days. While an itinerant symposium presented some logistical challenges, the benefits were that Re@ct directly engaged a diversity of physical locations across the city center, thus bringing both international visitors and locals together to connect within our community, and with its culture and history.

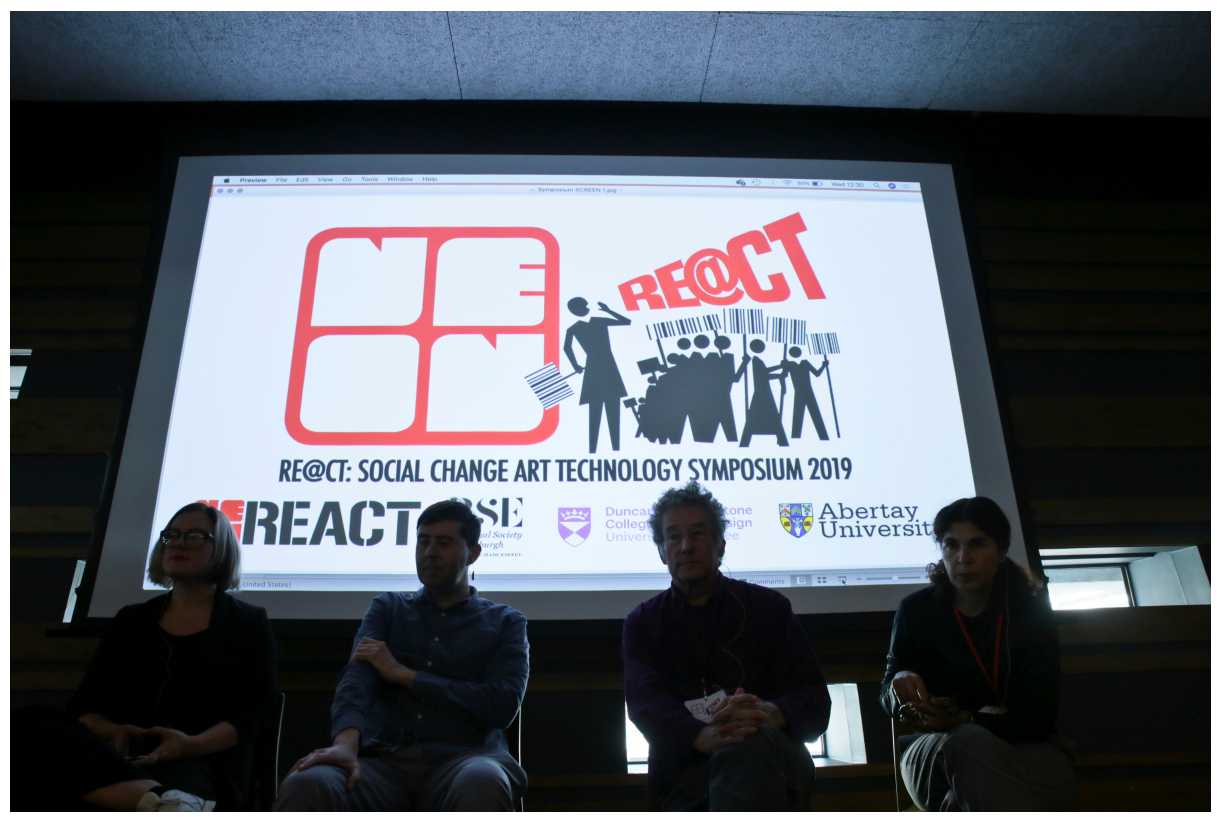

\section{Figure 1. “Why Now? Learning from Activist Video of the 1970s \& 80s,” panel presentation at the $V \& A$ Museum of Design. Photo: Kathryn Rattray}

The first day was held at the V\&A Museum of Design Dundee, Scotland's newly built design museum and architectural jewel located prominently on the waterfront that in the past decade has become a symbol of the cultural and economic regeneration of the city. For the morning of day two, we sited ourselves in the community hall of West Church near the University of Dundee campus, a location that would have been entirely fitting in a Wes Anderson film, with its folding 
chairs and 1970s décor; for the afternoon, the sessions moved to the city center, to Chambers East, a grand nineteenth-century Victorian hall that once served as a meeting place for the "Jute Barons" and power brokers of Dundee. Our third and final day was held at the Steps Theatre in the Wellgate Centre Library, located in one of two shopping centers in central Dundee (this is also where many of the festival exhibitions, actions, and performances took place). Thus, the Re@ct symposium moved about the city from spaces associated with high culture, religion/community, commerce/power, and learning, showing the different faces, transformations, and stories that Dundee has embodied in recent years.

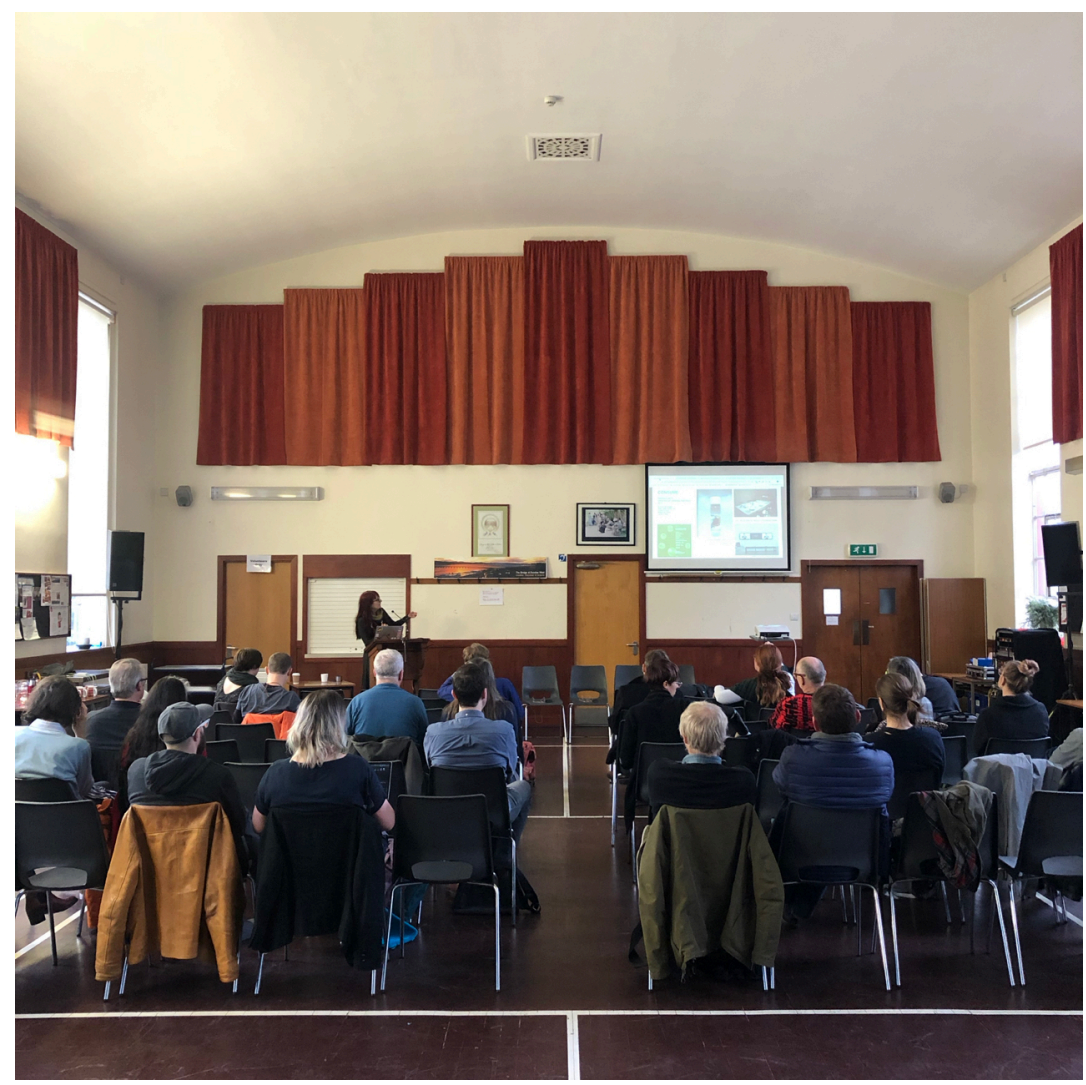

Figure 2. Amanda McDonald-Crowley presenting her keynote address “Artists and Food Systems: Towards Sustainable Futures" at West Church Dundee on day two of the symposium. Photo: Joseph DeLappe

The Re@ct symposium featured a diverse range of speakers, including six internationally recognized keynote speakers (four women, two men) and twenty-four presenters scheduled across six panels. Speakers included some of the most relevant international and national experts in the field. The sessions and keynotes explored pressing topics in the field, including AI, global warming, accessibility, sustainability, representation of minorities and marginalized groups, copyright, drone warfare, surveillance, and decolonization. Some presentations focused on underrepresented groups or specific countries, uncovering new knowledge. Speakers presented 
experimental digital media and approaches, discussing potential outlets, possible threats in the field, and emerging opportunities for activist digital practices and scholarship.

This issue of Media- $N$ includes a selection of the papers and artist talks presented at the symposium, with the aim of representing a range of the most relevant and pressing topics and presenting opinions by established theorists and practitioners as well as new voices and perspectives.

The article by Italian London-based curator Giulia Casalini explores and discusses how digital arts have been used as empowering tools by marginalized groups, providing an overview of early queer interventions in the realm of digital arts and showing how they have tackled a vast range of issues including discrimination, racism, ecology, and violence; Casalini discusses the case study of micha cárdenas' Sin Sol, an augmented reality game that engages with the dramatic impact of climate change on marginalized groups.

Scottish artist B.D. Owens discusses issues of surveillance in relation to his ongoing project the \#UndesiredLine, retracing artists and theories that have informed his approach - including Janet Cardiff and David Rokeby - and unpacking the advantages and pitfalls of the use of social media in the project.

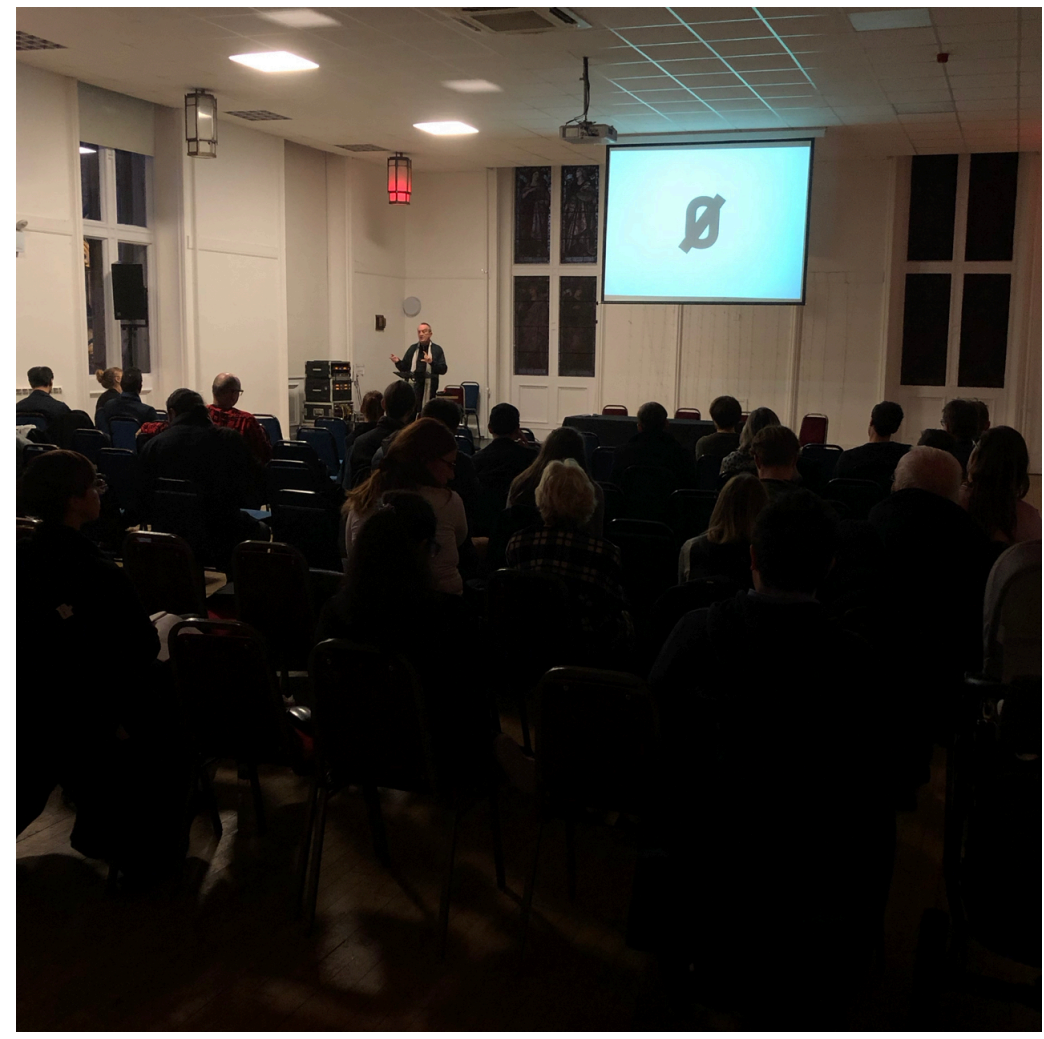

Figure 3. Prof. Sean Cubitt presenting his keynote address "Ecocritical Media Arts and the War on Terra” at Chambers East. Photo: Joseph DeLappe 
Media ecology is at the center of media art theorist Sean Cubitt's piece, which was presented as one of the six keynote lectures at the symposium. Some authors engage with notions of artist or activist-led interventions to address political, societal, and economic problems. For example, drawing from Aby Warburg, Georges Didi-Huberman, and Jacques Derrida, activist Fernando Martín Velazco discusses an intervention that used fake news to revive an historical newspaper, in order to address the ongoing drug war in Mexico. Joanna Walsh experiments on a performative online persona from a feminist point of view.

Irish artist Conor McGarrigle and US artist Dennis Delgado engage with issues and pitfalls that have emerged from the rise of machine learning and AI. McGarrigle examines AI biases through an analysis of his art project \#RiseandGrind, where a bot tweets content generated by a recurrent neural network that was trained from Twitter hashtags to identify a specific filter bubble (embodied neoliberal precarity). Drawing from Gilles Deleuze and Felix Guattari's theories, Delgado in his article The Dark Database: Facial Recognition and Its "Failure" to Enroll problematizes the discriminating results of facial recognition algorithms in the context of the representation of Black people, thereby addressing the culture which produced these representations.

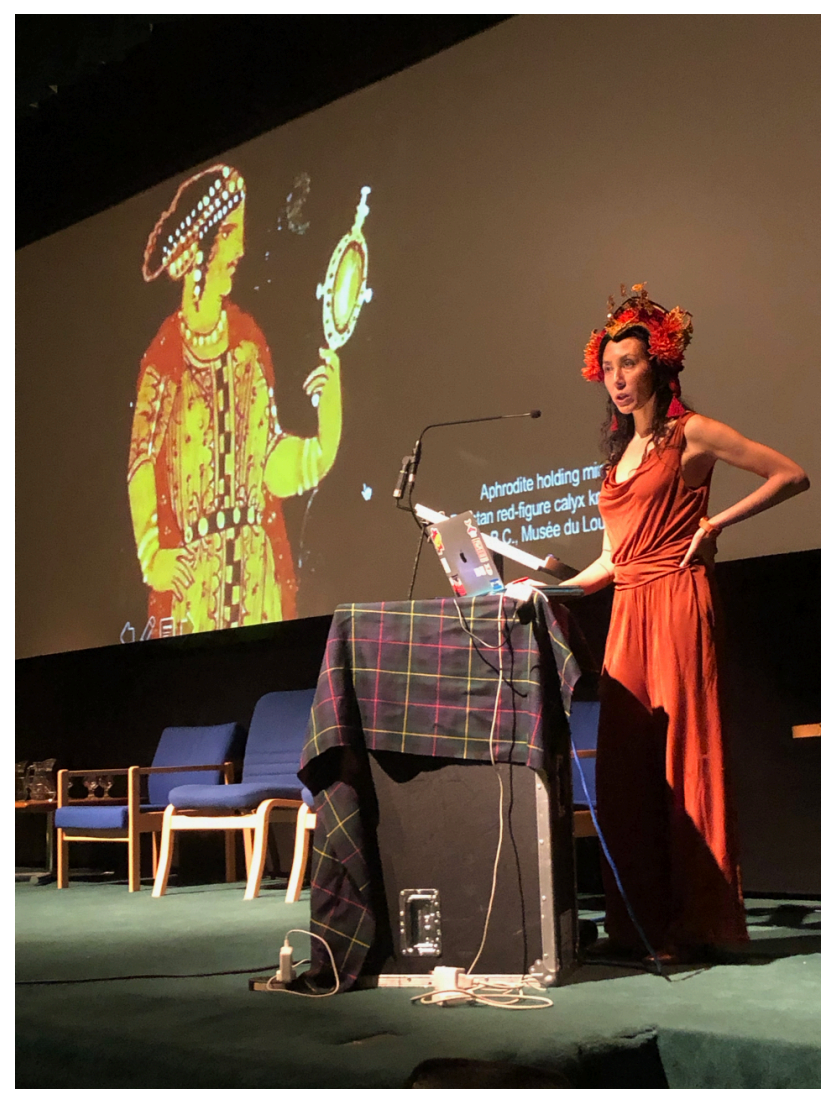

Figure 4. Marisa Morán Jahn presenting her keynote address, "The Copper in My Cooch and Other Technologies” at the Steps Theatre. Photo: Joseph DeLappe 
This collection is rounded out by several visual essays and reviews, including Mahwish Chishty's keynote presentation describing her creative approach to examining and questioning the growing use of weaponized drones in Pakistan, as well as Marisa Morán Jahn's keynote, which considers the provenance of the copper used to make her IUD. She takes a critical and performative look at the complexities of globalization and resource extraction and arrives at a place where the personal becomes the political.

Taken together, these articles offer a kaleidoscope of different topics and approaches, contributing to current debates and conversations, inspiring new ones and making a positive and tangible impact in the field.

When we set out to organize the Re@ct symposium, it was clear that there was an urgent need to provide a platform for the consideration of digital art and activism in our contemporary social and political contexts. We could not predict how much the world would change in the months that would follow. Thinking back to November 2019 and the state of the then-chaotic world (Brexit, Donald Trump, the refugee crisis, the worsening climate crisis...), we realize that what has happened since then has only magnified the need to continue to recognize, support, question, and work to find ways to foster positive change. We came to this project with an intense belief that digital artists play a crucial role in helping us to "react," to fight for what is right and make positive change a reality. The Re@ct Symposium represented a unique opportunity for digital artists to come together, less around common themes and more around the possibilities, successes, and challenges that emerge when artists work from the notion that what they do matters and, in the course of things, might even change the world.

\section{ACKNOWLEDGEMENTS}

We would like to take the opportunity to thank everyone who contributed to the symposium and to this issue in these very difficult times. This research project and symposium would not have been possible without the generous support of our funders and partners: Abertay University, the Duncan of Jordanstone College of Art \& Design at the University of Dundee, the University of Glasgow, the Royal Society of Edinburgh, and NEoN Digital Arts Festival.

\section{AUTHOR BIOS}

Joseph DeLappe is Professor of Games and Tactical Media at Abertay University, Dundee. He has worked with electronic and new media since 1983. His work in online gaming performance, sculpture, and electromechanical installation has been shown throughout the United States and abroad, including exhibitions and performances in Australia, the United Kingdom, China, Germany, Spain, Belgium, the Netherlands, Mexico, Italy, Peru, Sweden, Canada, and elsewhere. He has lectured throughout the world regarding his work, including at the Museum of Modern Art in New York City. His works have been featured in The New York Times, The Australian Morning Herald, Artweek, Art in America, and in the 2010 book from Routledge entitled Joystick Soldiers: The Politics of Play in Military Video Games, among many others. He has authored two book chapters: "The Gandhi Complex: The Mahatma in Second Life," in Net Works: Case Studies in Web Art and Design (New York: Routledge, 2011), and "Playing Politics: Machinima 
as Live Performance and Document," in Understanding Machinima: Essays on Filmmaking in Virtual Worlds (London: Continuum, 2012). In 2017 he was awarded a Guggenheim Fellowship.

Dr. Laura Leuzzi is an art historian, curator, and Researcher at the SARAS Department at Sapienza University of Rome. Currently she is a Visiting Research Fellow at Abertay University, Dundee and a Visiting Research Fellow at Gray's School of Art, Robert Gordon University, Aberdeen. Prior to that she was Research Fellow and Co-Investigator on the AHRC-funded project "Richard Demarco: The Italian Connection" (2018-2020; DJCAD, University of Dundee). She was postdoctoral researcher on the AHRC-funded projects "EWVA: European Women's Video Art in the 70s and 80s" (2015-2018) and "REWINDItalia: Artists' Video in Italy in 70s and 80s" (2011-2014), both at DJCAD, University of Dundee. She is the author of articles and essays in books and exhibition catalogues and has conduction research focused on early video art, European video art histories, art and feminism, and new media. She has curated exhibitions, events, and screenings at CCA, Glasgow; The Showroom, London; The Nunnery Gallery, London; MAXXI, the National Museum of 21st Century Arts, Rome; Walcherturm, Zurich; Horsecross Arts, Perth; The Summerhall, Edinburgh; The Glasgow Women's Library; The Lethaby Gallery, Central St Martin, London. She co-edited REWINDItalia: Early Video Art in Italy (London: John Libbey, 2015) and EWVA: European Women's Video Art in the 70s and 80s (London: John Libbey, 2019). 